\title{
El papel de la universidad en el pensamiento de Ignacio Ellacuría: lecciones y actualidad
}

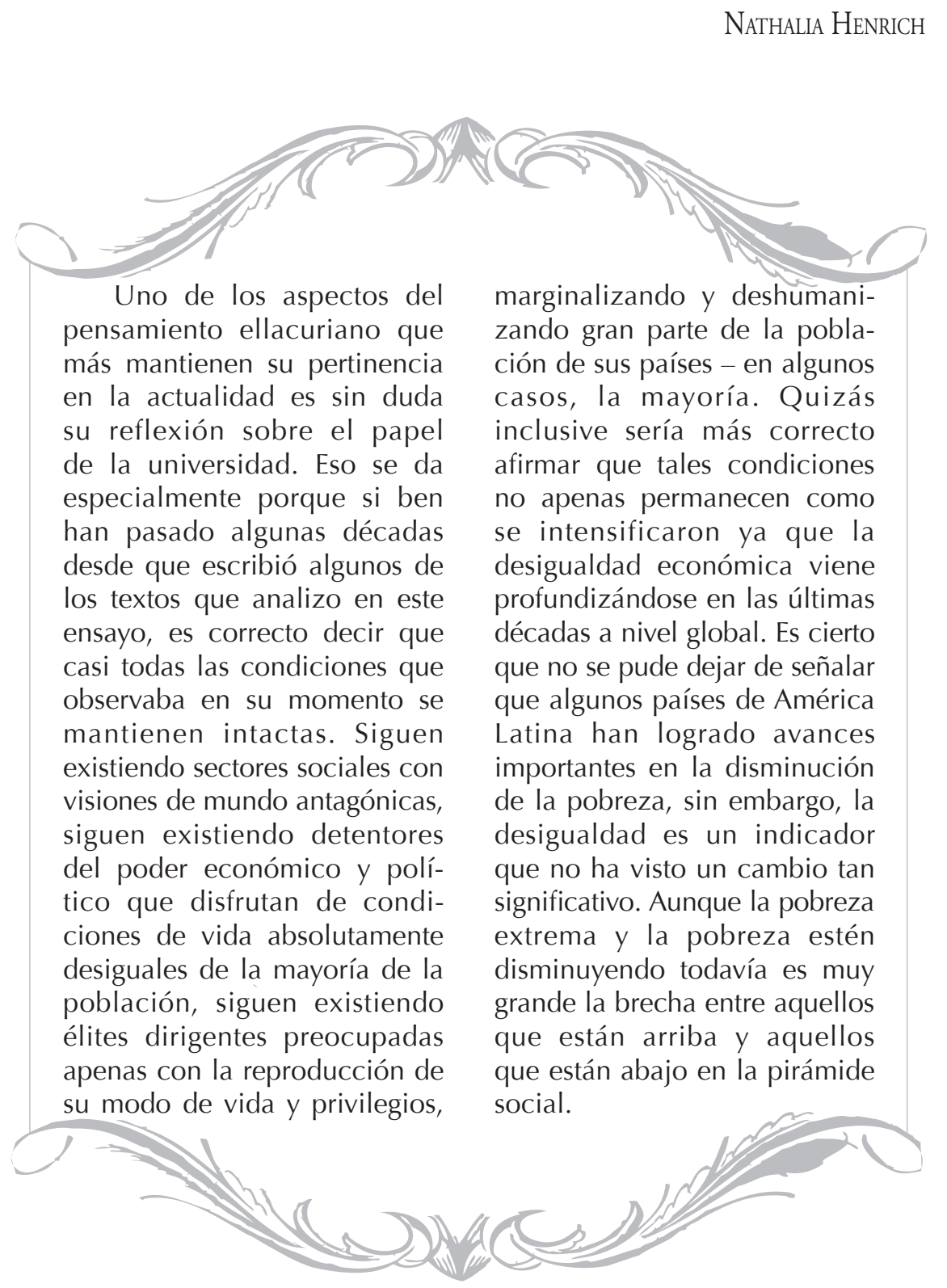


Tomando en cuenta este contexto es altamente relevante discutir sobre el papel que debe tener la universidad en las sociedades, especialmente en sociedades tan desiguales como las latinoamericanas. Ya en 1975, reflexionando sobre los diez años de la fundación de la Universidad Centroamericana "José Simeón Cañas", su rector en ese momento afirmaba que el error histórico más grande de la universidad latinoamericana había sido ajustarse a las demandas de una educación neutra, atemporal y ahistórica, comprometida con el mantenimiento de las estructuras vigentes. Para él, que la acción universitaria fuera limitada a brindar una carrera profesional a un núcleo ínfimo de la población que ya detenía privilegios claros era también limitar las potencialidades de servicio que la universidad podría brindar al pueblo salvadoreño en aquel momento. (SAMOUR, 2007, p. 209).

Esta reflexión se puede aplicar a la situación actual en diversos países en donde si por un lado la oferta educativa universitaria se expande, por otro, la calidad de la enseñanza proporcionada no es compatible. Por calidad entiendo no apenas la calidad del contenido académico impartido ni la capacidad de los profesores que lo dictan sino la capacidad de generar conocimiento y no apenas reproducirlo. Sobre todo, la capacidad de generar conocimiento que sea útil para la transformación social y sea un componente fundamental de desarrollo no apenas en el sentido de crecimiento económico.

Un ejemplo es la expansión de la educación privada en diversos países. Por detrás de la proliferación de universidades privadas que ofrecen cursos a bajos costos y en tiempo reducido, está la lógica característica de la civilización del capital, la búsqueda incesante por la reproducción de estructuras sociales que marginalizan a gran parte de sus ciudadanos. La formación que se ofrece en esos espacios apenas ayuda a profundizar los procesos de explotación y a crear formas de opresión más sofisticadas en la medida en que buscan apenas formar masas de trabajadores técnicamente hábiles y social y políticamente inactivos. La educación más barata que es ofrecida está pensada para atender a las camadas más pobres de la población que ven en el acceso a la universidad su única oportunidad de ascensión económica y social. Esas universidades venden el sueño de "una vida mejor" a través del estudio, teniendo la premisa del profesionalismo por detrás.

Entre otras, hay dos principales críticas que pueden ser dirigidas a estas instituciones con base en los conceptos ellacurianos. Tengo en mente aquí fundamentalmente los dos peligros señalados por Ellacuría (1982) el profesionalismo y el elitismo. Los dos están 
intrínsecamente ligados ya que la enseñanza ofrecida no será suficiente para que sus egresados realmente puedan insertarse en el mercado laboral con capacidad de competir con los miembros de las élites que disfrutaron de una formación compatible con su posición social. Eses nuevos profesionales estarán destinados casi siempre a las funciones subalternas, con poco o ningún poder decisorio y de bajo o ningún impacto social, ya sea para sí mismos o para su entorno más inmediato. Además, la educación superior de bajo costo fomenta la idea de que apenas a través del esfuerzo personal se puede lograr la superación de una condición marginal en la sociedad y que las estructuras no tienen un peso en esa condición. El resultado es claramente desmovilizador desde el punto de vista de la búsqueda de la liberación.

Cuando se habla de un paradigma liberador en la universidad es muy común que parte del rechazo a la idea de una universidad "politizada" esté basada en el entendimiento equivocado de que es posible la construcción de conocimiento neutro y que decisiones políticas servirían apenas para generar desigualdad. Así, se aleja la posibilidad de que el conocimiento desenvuelva todo su potencial transformador con miedo a que al hacerlo se esté politizando una institución que tiene como objetivo servir "a todos" y de esta manera se favorecen a ciertos sectores sociales en detrimento de otros. Ellacuría (1975) tenía una respuesta clara a estas posturas y que valdría la pena reconsiderar actualmente. Para él, el sentido último de una universidad debe ser medido a través del criterio de su incidencia en la realidad histórica en la que existe y a la que sirve. O sea, a través de un criterio eminentemente político. Es más, la dimensión política de la universidad no es apenas innegable sino que es importantísima para su propia orientación.

La misión política de la universidad es Ilamada por Ellacuría (1975) "el modo universitario de realizar la tarea de liberación". Su razonamiento es simple: ya que no es posible anular la existencia de diferencias en la sociedad en dado momento histórico, la universidad necesita ponerse al lado de los sectores que son la mayoría cuantitativamente y que también representan más auténticamente los intereses generales. Esas mayorías son las que sufren directamente con la deshumanización generada por la civilización del capital y por lo tanto es hacia esas mayorías oprimidas que la universidad necesita orientarse y no a las clases dominantes. Aunque esté pensando específicamente en la realidad de El Salvador entre los años 60 y 80 , todavía es posible establecer un paralelo con lo que pasa en varios países latinoamericanos hoy en día. Como he mencionado, si bien se 
ha logrado disminuir la pobreza en algunos países, falta mucho por hacer para mejorar la inclusión social y la participación política de porciones importantes de la población.

Por ver esta realidad, Ellacuría (1975) defendía una universidad que claramente tomaba partido, que decidía por un lado y era el lado de las masas oprimidas. En el contexto de una sociedad dividida y con intereses claramente antagónicos como era El Salvador en ese momento, la opción le parecía muy clara, era necesario que en el horizonte de la universidad estuvieran los "intereses científicamente procesados" de las mayorías oprimidas. Una de las características del modo universitario de realizar la tarea de liberación reside en que las mayorías oprimidas son el horizonte de la actividad universitaria. Se trata de hacer una opción por esa parcela de la población y de tener el cambio estructural de la sociedad como finalidad.

Según él, se debe hacer de la cultura el campo propio de la universidad. La cultura entendida no como patrimonio de las clases cultas, como es generalmente entendida. La cultura es concebida por Ellacuria (1975) como el "cultivo de la realidad", como acción cultivadora y transformadora de la realidad. Esta cultura creada en el ámbito universitario proviene de una necesidad de acción que debe generar una acción transformadora de los sujetos, de su entorno natural e histórico. Por eso la cultura generada en la universidad tiene un sentido eminentemente práxico. Es importante tener en cuenta que es el sentir profundo del pueblo el que debe tener resonancia en la cultura crítica y libertadora que debe formarse en la universidad. Sus intereses, necesidades, valores, apetencias, sentimientos, son aspectos que la cultura debe tomar en cuenta y tratar de representar. Los muros de la universidad no deben servir para separar ni el conocimiento generado ahí ni debe alejarla de su entorno social.

Se entiende más claramente su planteamiento cuando explica qué es la cultura nacional, esa cultura que debe ser producida en la universidad. Para Ellacuría (1975), no se debe confundir cultura nacional con folklore nacional, aunque el folklore pueda aportar cosas importantes a esta. La cultura no es estática y debe estar orientada hacia el futuro, la transformación. En ella está en juego la realidad histórica del país, una realidad que está en continua construcción y para la que contribuyen muchas $y$ diferentes fuerzas y factores. Otra cara fundamental de la cultura es la de construcción de nuevos valores que ayuden a descubrir los valores que legitiman la dominación. En este sentido, la cultura actúa como crítica ideológica, trae a la luz los elementos legitimadores 
de la dominación, ayudando a romper con la cultura dominante. (SAMOUR, 2007, p. 211). De esta manera es que la universidad puede cumplir con el papel de promover una conciencia crítica y al mismo tiempo creadora, tal cual deseaba Ellacuria.

Un punto importante que destaca Ellacuría es que la actividad intelectual debe siempre someterse a las exigencias de la realidad y tratar de superar cualquier esquema ideologizante. (SAMOUR, 2007, p. 225). Eso tiene ligación directa con la naturaleza y las características de la función liberadora que tiene en mente y de la cual la universidad es un instrumento. No se pretende desarrollar ni una filosofía que logre liberar a unos pocos miembros de la clase ilustrada ni tampoco una filosofía popularizada que fuera simplemente apropiada por las masas sin mayor reflexión. El proceso de apropiación de la filosofía por las masas como su ideología liberadora debe ocurrir en su momento pero a través de un proceso deliberativo, de manera que no se vuelva dogmático. Hay una preocupación con que la nueva filosofía que propone no se transforme apenas en otra fuerza dogmática y opresora-represora sobre las mayorías populares.

El papel de la universidad es entendido adentro del mismo esquema. No parte de la premisa de quien está jerárquicamente superior en una escala social o intelectual y que quiere enseñar el camino hacia la liberación. Por eso es a través de una colaboración intelectual estrecha entre los individuos, que son al mismo tiempo sujetos y objetos de la filosofía liberadora, es que se alcanzará plenamente la función liberadora. (ELLACURIA, 1985).

Para eso también es importante que la universidad huya de la ideologización. El fenómeno de la ideologización tiene un potencial muy peligroso porque está intrínsecamente relacionado con las realidades sociales que configuran las conciencias colectivas e individuales. Eso conlleva a que todos los sistemas os subsistemas sociales busquen la legitimación ideológica como parte fundamental de su subsistencia y/o de su buen funcionamiento. Si un sistema es injusto, cruel o apenas inerte, el aparato ideológico pasa a configurarse como un aparato de ideologización, que trata de mantener el statu quo apenas para sobrevivir, buscando resaltar lo que tenga de bueno y ocultar el malo del sistema. (ELLACURIA, 1985).

La "universidad distinta" que defiende Ellacuría consiste en una institución que responda a su misión histórica y cumpla con su inexorable misión política, además de probar su eficacia política en la configuración de una nueva sociedad y del poder del Estado. 
Es una universidad que quiere ir más allá sin dejar de tomar en cuenta la necesidad de promover el desarrollo nacional entendido como crecimiento económico. Es una institución que mantiene un ideal de desarrollo integral y busca promover el desarrollo de todos los seres humanos. Como afirma Samour (2007, p. 208) "el concepto de libertad es el concepto que mejor define su idea de desarrollo integral". Las ideas de Ellacuría están puestas, su actualidad es clara y su visión necesita mantenerse viva. Universidades con el compromiso de educar y formar ciudadanos para la libertad es algo de que Latinoamérica ya no puede prescindir.

\section{Referencias Bibliográficas :}

os ELLACURIA, I. Diez años después, ¿es posible una universidad distinta? ECA, n. 324-325, p. 605-628, 1975.

os ELLACURIA, I. Universidad, derechos humanos y mayorías populares. ECA, n. 406, p. 792-802, 1982.

os ELLACURIA, I. Función liberadora de la filosofía. ECA, n. 435-436, p. 45-64, 1985.

os SAMOUR, H. Universidad para la liberación: la proyección social de la UCA. Revista Realidad, n. 112, p. 207-228, 2007. 